\title{
A Study on Optimized Function Modules of Quality Courses for Online Education
}

\author{
LIU, Zhixuan \\ Dean of Studies \\ Shaanxi Radio \& Television University \\ Xi'an, Shaanxi 710119, P. R. China \\ E-mail: liuzhixuanlx@163.com
}

\begin{abstract}
With the booming of online education, the construction of teaching resources has become a priority among all in modern distance education. High-quality online courses are deemed increasingly as an outstanding feature of online education aiming to carry out teaching quality project in higher learning institutions; however, universities offering online education have to pay high attention to the poor utilization of quality online courses. The key to this phenomenon is the problem encountered in the way online curriculum module is presented. This article, starting out from actuality and problems concerning the building of domestic online courses and based on research and analysis of national high-quality online courses and related online curriculum modules, proposes a "comparative and optimized presentation" mode to ensure applications of this mode will further the development and construction of high-quality online courses in universities that have offered online education, and most of all, to provide a potent factual basis for increasing utilization of online courses.
\end{abstract}

Keywords-online education; quality courses; function module; mode of presentation; comparative optimization

\section{INTRODUCTION}

Since 1998 when modern higher distance education program was officially launched in China, considerable progress has been made in the build-up of teaching resources, especially of high quality ones led by excellent online courses that have driven more online education institutions into the line-up of modern distance education providers with great-leap-forward development, including Tsinghua University, Zhejiang University, Nankai University, Tongji University, the Open University of China, etc. In the Notice of Applying for National Quality Courses in 2007 (Document No. 25 [2007], General Office, MOE) issued by the Ministry of Education (MOE) in April 2007, quality courses for online education were incorporated for the first time into national quality curriculum construction system and have since promoted teaching activities, educational informationization and teaching resources sharing and application among teachers in universities. As a result, construction of quality courses for online education in China has occupied a core position in university teaching quality project of distance education. [1] In particular, it is worth noting that achievements made during quality online curriculum construction are used by universities and colleges as a vanity project for the purposes of publicity, qualification evaluation and expansion of their branch schools. By the end of 2012, quality online courses have been chosen four times by the Ministry of Education through public appraisal; this honorary title has been awarded to 209 courses from 68 universities and colleges nationwide (49 courses in 2007, 50 in 2008, 50 in 2009 and 60 in 2010). These courses prove true to the reputation on the ground that they really comply with such curriculum construction objectives as first-rate faculty team, excellent teaching contents and methods, practical textbooks and best teaching management [2] in terms of overall design, course contents and educational means. In the process of construction, appraisal and application of these courses, however, it is not hard to see the special concern for quality online courses drawn to teachers and students for their essential roles in online education platform; what effect these courses may lead to is the ultimate purpose of our top concern. Facts have shown that application effect of a course depends largely on how its learning modules are presented, and that the utilization rate or click rate and download rate of its learning resources may rely heavily on mode of presentation. This proves substantial role of learning resources utilization rate in assuring and raising distance education quality. For this reason, presentation mode of online high-quality curriculum modules is crucial to optimizing distance education teaching process and improving teaching quality of distance education in China, and especially to the healthy development of open and distance university program carried out in China.

\section{THE STATUS QUO OF QUALITY COURSES FOR ONLINE EDUCATION}

\section{A. Application of function modules of national quality online courses}

Online curriculum construction in China has currently transformed from the original modification of textbooks and classrooms into integration of teaching contents and teaching activities [3]. To a large extent, the existing 209 national quality online courses that can be set and offered by various modules in accordance with appraisal target system are playing a leading demonstration role in the construction of online courses for modern open higher education. 
TABLE I. SETTING OF FUNCTION MODULES OF NATIONAL QUALITY COURSES FOR ONLINE EDUCATION AND STUDENTS' CLICK RATE (TAKE UNIVERSITIES AND COLLEGES IN SHAANXI)

\begin{tabular}{|c|c|c|c|c|c|c|}
\hline FM & LG & TG & CS & EAS & IP & AP \\
\hline CTR & $61 \%$ & $76 \%$ & $52 \%$ & $78 \%$ & $71 \%$ & $68 \%$ \\
\hline
\end{tabular}

Key: FM=function module, LD=learner guide, TG=teacher guide, CS=case study, EAS=exercise and selftest, $\mathrm{IF}=$ interactive platform, $\mathrm{AP}=$ average percentage, $\mathrm{CTR}=$ Click-through-rate

The above table shows that the case teaching module earns the lowest CTR of $52 \%$, the exercises and self-test module earns the highest CTR of $78 \%$, and the average CTR of all modules is $68 \%$, which is evidently much too far away from objectives of online courses for distance higher education and also reveals fundamental problems in presenting function modules of quality courses for online education. Yet, considering 14-year history of online education in China, the average CTR of five modules above $68 \%$ has already manifested fairly good results in building teaching resources of modern distance education that have lead to the expansion of quantity and capacity of open education providers in China. Unfortunately, the achievements we have made in building quality online courses for modern distance education in China seem incomparable with those of the western countries including the UK, the US, France, Australia and Canada that initiated distance education much earlier. The reason for this disparity may be traced back to many problems frequently encountered by front-line teachers of online courses, such as unsuitable teaching plan for adult learning, inadequate use of advanced teaching technology, indefinable setting of site navigation, poor maintainability and upgradeability of curricular contents and materials, unenlightening guidance and help tip for learners on curricular website, less interactive online courses and insufficient original video and audio resources [4]. These problems need urgent improvement and innovation by reference to the experiences of developed countries in building online courses for distance education.

\section{B. Problems in building non-national quality courses for} online education

- 1)Applications of non-national quality online course resources

As is known to all, rapid expansion of online education in China has become a global concern. According to investigation and analysis by December 2012, 100\% of 68 universities and colleges offering modern distance higher education programs have control over or deep introspection of student sources. Nearly all of them have decided to give top priority to improving teaching quality; meanwhile, construction of high-quality teaching resources becomes essential to the construction of teaching connotation. Take Shaanxi Radio \& Television University as an example, by December 2012, the total capital cost spent on online courses in recent three years amounted to 2.79 million Yuan RMB (incl. 0.6 million in 2010, 0.8 million in 2011 and 1.3 million in 2012); honorary titles in this respect included 3 first prizes, 15 second prizes, 14 third prizes and 45 honorable mentions in the Tenth National Multimedia Courseware Contest 2010, the Eleventh National Multimedia Courseware Contest 2011 and the Twelfth National Multimedia Courseware Contest 2012. It follows that teaching resources of online courses in China are being developed and constructed in a planned, purposeful, conscious and systematic way. However, by the analysis of applications of online courses developed and activated by online colleges of 67 regular universities, the Open University of China and 44 provincial radio and television universities, it is easy to see that problems concerning students' application of these resources are absolutely incredible, especially including low utilization of online course resources. This merely reflects unilateral willingness of universities and by no means measures up to visions building teaching and learning resources for modern distance education in real sense.

TABLE II. STATISTICS ON APPLICATION OF NON-NATIONAL QUALITY ONLINE COURSES FOR MODERN DISTANCE HIGHER EDUCATION

\begin{tabular}{|c|c|c|c|}
\hline UA C & CR & DR & ANOS \\
\hline OCOCU & $42 \%$ & $38 \% \%$ & $40 \%$ \\
\hline OU of China & $52 \%$ & $41 \%$ & $47 \%$ \\
\hline PRTVU & $38 \%$ & $29 \%$ & $34 \%$ \\
\hline
\end{tabular}

Key: UAC=universities and colleges, $\mathrm{CR}=$ click rate, $\mathrm{DR}=$ download rate, ANOS=average number of students, OCOCU $=$ online colleges of conventional universities, PRTVU=provincial radio and television universities

Obviously, although considerable resources of manpower, materials, finance and time are put into the construction of online courses for distance higher education in China, application of these courses is far from satisfactory, resulting in serious waste of resources to a large extent. Either in online colleges of conventional universities or in the Open University of China as well as other 44 provincial radio and television universities (rtvu), the average click rate and download rate for online courses remains below $50 \%$, with a maximum of only $47 \%$, indicating serious problems in the making of online courses for distance higher education in China. Hardly will online courses construction witness a sound development until we get increasingly serious about how to analyze and address it.

- 2)Necessity of research on the mode of presenting online course function modules

According to searches in officially published periodicals and Sohu.com, Google.com, Baidu.com, Netease.com and CNKI.net, extremely limited research activities and results are found in building online education courses; in particular, few treatises are found directly addressing quality online courses for distance education.

TABLE III. STATISTICAL LIST OF NETWORK INFORMATION ON QUALITY COURSES FOR ONLINE EDUCATION (DECEMBER 2012)

\begin{tabular}{|c|c|c|c|c|c|c|}
\hline $\begin{array}{c}\text { Sites } \\
\text { Cat.. }\end{array}$ & Sohu & Google & $\begin{array}{c}\text { Bai } \\
\text { du }\end{array}$ & $\begin{array}{c}\text { Net } \\
\text { ease }\end{array}$ & CNKI & Tot \\
\hline JA & 6 & 10 & 12 & 5 & 18 & 51 \\
\hline AC & 3 & 3 & 4 & 3 & 3 & 16 \\
\hline Total & 9 & 13 & 16 & 8 & 21 & 66 \\
\hline
\end{tabular}


Key: JA= Journal articles, $\mathrm{AC}=$ academic conference, Cat.=category

Over the past dozen years of distance higher education in China, more than 100 thousand full-time teachers have engaged in teaching distance education courses, but the statistical results above have shown that greater efforts have to be made to implement research, exchange and innovation of online courses especially in 68 conventional universities and colleges that have offered online education programs and in the Open University of China, Shanghai Open University and Beijing Open University founded in 2012, and decision makers of which have to make deep introspection on how to develop online courses. If we search "high-quality function modules of online courses" on aforesaid websites, we will find only 12 related articles but none themed consistently; moreover, many viewpoints proposed in these articles are largely equivalent to traditional online courses, quite different from the function modules necessary to students' autonomous learning. While application of online courses may be strictly dominated by various factors, the final of the Twelfth National Multimedia Courseware Contest has revealed that the key factor is how to present function modules of online courses. Without exception, nearly all multimedia courseware contestants who won the first prize at least had scored their key points in this respect. Unfortunately, not a single research paper on mode of presentation of online course functions has so far been found in domestic search engines. Nor has this drawn high attention from the leadership of online education universities or from front-line developers of teaching resources.

\section{STRATEGIES FOR RESEARCH ON MODES USED TO PRESENT FUNCTIONAL MODULES OF ONLINE COURSES}

As is known to all, online courses for distance education must be oriented to students' autonomous learning and subjective needs. The construction of function modules in online courses has been universally acknowledged either in theory or in practice. Among millions upon millions of online courses developed nationwide, $100 \%$ of them are functionally modularized as required by evaluation indexes at both national and provincial levels. For a variety of reasons, few of about 100 thousand teaching staff in distance education have ever inquired into or written about this problem according to investigation from academic conferences and journal articles. This becomes our top concern on the ground that: 1) the click rate and download rate of curriculum modules can illustrate application of online courses during the development of open education; 2) research project and teaching reform project carried out by competent authorities of education administration at all levels can reveal attention paid by governmental sectors to the building of online courses for open education; 3) searching research papers on main websites and CNKI can help uncover innovative viewpoints and constructive feedbacks of education researchers and front-line teachers; and 4) special activities, especially including curriculum review and academic conference, can help identify problems in building online courses for open education and related improvement strategies. Unfortunately, there is no ready solution to the key problems involved in four strategies, nor is there a viewpoint corresponding to the research topic of this article-the mode of presenting function modules of online courses. According to 209 national quality online courses and those developed by the Open University of China, by adopting literature review method, content analysis method and combined quantitative and qualitative analysis method, considering actual scoring results of finals of the Twelfth National Multimedia Courseware Contest, and after browsing and making comparative statistics of online courses available on websites of the Ministry of Education and all universities, this article purposefully analyzes the mode of presenting function modules of online courses, seeks for a shortcut and optimized mode of presenting function modules of online courses, and takes the optimized mode as a breakthrough for organic unity of the quantity and quality of online courses to ensure optimal utilization of teaching and learning resources from online courses and to comprehensively facilitate great-leap-forward development of distance higher education in China by means of high quality online courses.

\section{OPTIMIZED ANALYSIS OF THE MODES USED TO} PRESENT THE FUNCTION MODULES OF ONLINE COURSES

The practice of distance education has proved that the construction of online courses must rely on the theory of distance education and aim at offering courses oriented to adult learners and helpful to their developing an autonomous learning habit. These courses, as fundamental basis for online learners to learn, are high quality teaching resources based on students' inner needs. The particular fascination of these resources lies in the effective mode of presentation of the function modules of online course. It is the distinctive mode that determines different utilization rate of curriculum resources, i.e. click rate and download rate.

\section{A. Module "Directions for Use"-prerequisite for increasing utilization of online courses}

While existing "directions for use" of online courses is written in various forms, it has only one purpose that is to tell learners how to utilize course resources. By analyzing the expressions of "directions for use" of online courses employed currently by online education universities in Shaanxi, we have discovered four types of expression, such as "text description"(TD), "commentary on video play”(COVP), “screenshots”(SS) and "screenshot and positioning presentation”(SSPP).

TABLE IV. SURVEY OF SATISFACTION WITH MOdE OF PRESENTING MODUlE “DiRECTIONS FOR USE” OF ONLINE EDUCATIONAL COURSES

\begin{tabular}{|c|c|c|c|c|}
\hline SR Types & TD & COVP & SS & SSPP \\
\hline OCOCU & $4 \%$ & $68 \%$ & $80 \%$ & $98 \%$ \\
\hline RTVUs & $4 \%$ & $60 \%$ & $82 \%$ & $96 \%$ \\
\hline Average & $4 \%$ & $64 \%$ & $81 \%$ & $97 \%$ \\
\hline
\end{tabular}


Key: SR=satisfaction rate, OCOCU=online colleges of conventional university, RTVU=radio and television university

As for presenting "directions for use" of online courses, the table above shows clearly that the mode of "screenshot and positioning representation" earns a satisfaction rate of $97 \%$, followed by "screenshot" mode with a percentage of $81 \%$; specific value between these two is only $16 \%$. Therefore, one of the two types can be used according to course nature and presentation technique of education technologies when the column "direction for use" of online courses is presented. Comparatively speaking, the presentation mode "text description" is not recommended because it earns a satisfaction of only $4 \%$ and is highly likely to affect students' learning of other modules.

\section{B. Module "Learner Guide" - key to increasing application of online courses}

Distance learners may feel all at sea about a new course, so a "Learner Guide" module is usually provided for each online course to help students learn effectively. Yet, as the module is presented in various forms, some students have gained little effect despite considerable time and energy because they are unfamiliar with the course while others have enriched their original knowledge hierarchy by making full use of quality resources because they know how to grasp key points and difficult points in the course of effective learning.

TABLE V. SURVEY OF SATISFACTION With MOdES OF PRESENTING “LEARNER GUIDE” MODULE IN ONLINE COURSES

\begin{tabular}{|c|c|c|c|c|}
\hline SR Types & TD & COVP & SS & SSPP \\
\hline OCOCU & $40 \%$ & $64 \%$ & $82 \%$ & $78 \%$ \\
\hline RTVUs & $42 \%$ & $64 \%$ & $74 \%$ & $78 \%$ \\
\hline Average & $41 \%$ & $64 \%$ & $78 \%$ & $78 \%$ \\
\hline
\end{tabular}

Key: SR=satisfaction rate, OCOCU=online colleges of conventional university, RTVU=radio and television university

The table above shows that commonly used types of presentation modes of "Learner Guide" in online courses include "text description", "text description and navigation link", "text description combined with video commentary" and "chairing teacher IP trisection screen navigation", among which, the last two types have earned highest satisfaction rate, $78 \%$. So it is recommended that one of the two modes be adopted when the column "Learner Guide" in online courses is presented.

\section{Module "Text Contents"-key point of increasing application of online courses}

In terms of online courses, this module is listed first of all modules as it contains enormous amount of information and covers many contents including the syllabus, teaching implementation plan, examination introduction, practical teaching rules, key/difficult points, content assists and extended learning programs. Presentation mode of course contents is of great importance when students are supposed to acquire all of these contents within limited time on a planned and purposeful basis.
TABLE VI. SURVEy of SATISFAction With Modes of PRESENTING “TEXT CONTENTS” MODULE IN ONLINE COURSES

\begin{tabular}{|c|c|c|c|c|}
\hline TR Types & PSBWD & PCWDZS & PBFC & PBFCA \\
\hline OCOCU & $4 \%$ & $18 \%$ & $36 \%$ & $94 \%$ \\
\hline RTVUs & $6 \%$ & $21 \%$ & $42 \%$ & $96 \%$ \\
\hline average & $5 \%$ & $19 \%$ & $39 \%$ & $95 \%$ \\
\hline
\end{tabular}

Key: SR=satisfaction rate, PSBWD=Presented by scroll bar in Word documents, PCWDZS=Presented by combining Word documents with Zoom in \& Zoom out search, PBFC=Presented by bullets fold and click, PBFCA=Presented by bullets fold and click audio, OCOCU= Online colleges of conventional universities, RTVUs= Radio \& television universities

Questionnaire suggests that only the presentation mode of "bullets fold and click audio" earned a satisfaction up to $95 \%$ while the other three modes did an average of $22 \%$, far from the former. Therefore, the presentation mode of "bullets fold and click audio" must be chosen for presentation of "text contents" during development of online courses. Only in this way can students effectively learn vast amount of text knowledge and achieve optimal learning effect with least time.

\section{Module "Video Classroom" - focus of increasing application of online courses}

Module "Video Classroom" is recognized as the highlight of online courses construction and also is a module demanding a great of time, manpower, effort, money and equipment during curriculum development. Generally, 40\% of budgetary resources for high quality online courses are appropriated for video courses in aspects of lecturer's qualifications, advanced recording equipment, techniques of recording personnel, knowledge and artistic quality of editors. In fact, the biggest difference in tens of millions of online courses developed for open education in China rests with the module "video classroom", presentation mode of which aims at a new height.

TABLE VII. Survey of SATISFaction With Modes of Presenting "VIDEO ClASSROOM" OF ONLINE COURSES

\begin{tabular}{|c|c|c|c|c|}
\hline SR Types & LV & EV & LTC & IPTS \\
\hline OCOCU & $20 \%$ & $36 \%$ & $40 \%$ & $63 \%$ \\
\hline RTVUs & $31 \%$ & $40 \%$ & $30 \%$ & $89 \%$ \\
\hline average & $25 \%$ & $38 \%$ & $35 \%$ & $76 \%$ \\
\hline
\end{tabular}

Key: SR=satisfaction rate, OCOCU= Online colleges of conventional universities, RTVUs $=$ Radio \& television universities, LV=live video, EV=edited video, LTC=live telecast classroom, IPTS= IP trisection screen

According to the survey, $62 \%$ of online courses developed by universities offering distance education programs have failed to be chosen as quality courses by competent education authorities at various levels due to lack of a video classroom; in particular, online courses that have tallied with standards for quality video lecture account for only $16 \%$. Consequently, the top quality video classroom has become a top concern of students in the process of autonomous learning; in addition, a lecturer's job title, age, clothes and eloquence may influence students' learning 
effect. It is thus advisable that the module "video classroom" be presented by the mode of "IP trisection screen - audio, video, audio, video and heading navigation switchover, free realization of Forward and Backward, full-range electronic teaching plan”. This mode earns a satisfaction rate up to $76 \%$ and can be by no means rivaled by any other mode.

\section{E. Module "Case Analysis" - a means to promote application of online courses}

Quite popular in online courses, this module is a method necessary to link theory with practice in the teaching process and also a flexible element in course development. More often than not, online learning is motivated by a lecturer's vivid discourse and interpretation. Since distance learners have few chances to talk face to face with the lecturer, they depend largely on module "case analysis" in online programs for understanding and applying what they are taught. For this reason, the "case analysis" module is supposed to not only contain carefully selected typical cases but also be presented in such a mode that may facilitate students' autonomous learning, just like a magnet draws students' learning interest into "case analysis".

TABLE VIII. SURVEY OF SATISFACTION WITH MODES OF PRESENTING "CASE ANALYSIS" OF ONLINE COURSES

\begin{tabular}{|c|c|c|c|c|}
\hline SR Types & PWD & PWDAC & PVPAC & PASC \\
\hline OCOCU & $4 \%$ & $48 \%$ & $86 \%$ & $97 \%$ \\
\hline RTVUs & $8 \%$ & $32 \%$ & $78 \%$ & $93 \%$ \\
\hline average & $6 \%$ & $40 \%$ & $82 \%$ & $95 \%$ \\
\hline
\end{tabular}

Key: $\mathrm{SR}=$ satisfaction rate, $\mathrm{PWD}=$ Presented by Word documents, PWDAC=Presented by combining Word documents with audio commentary, PVPAC=Presented by combining video play with audio comments, PASC=Presented by combining animated simulation with comments, OCOCU = Online colleges of conventional universities, RTVUs= Radio \& television universities

From the table above, the presentation modes "animated simulation and comments" and "video play and audio comments" are favorably received by students, with satisfaction rates up to $95 \%$ and $82 \%$ respectively; in contrast, the "Word document" mode should be absolutely avoided to present the "case analysis" module in online courses, for it earns a satisfaction rate of only $4 \%$.

\section{F. Module "Picture Show" - lubricant to increase application of online courses}

The teacher can transform text contents into pictures in accordance with textbook contents, and particularly gather and use considerable amount of picture materials from course contents for concretization of abstract knowledge. It follows that the "picture show" module as an important part of online courses can help arouse students' learning interest and visualize, emotionalize abstract contents in textbook.
TABLE IX. SuRVEY OF SATISFACTION WITH MODES OF PRESENTING "Picture Show" of Online Educational Courses

\begin{tabular}{|c|c|c|c|c|}
\hline SR Types & PP & ETP & EPA & EPABM \\
\hline OCOCU & $30 \%$ & $46 \%$ & $78 \%$ & $100 \%$ \\
\hline RTVUs & $36 \%$ & $56 \%$ & $86 \%$ & $100 \%$ \\
\hline average & $33 \%$ & $51 \%$ & $82 \%$ & $100 \%$ \\
\hline
\end{tabular}

Key: $\mathrm{SR}=$ satisfaction rate, $\mathrm{PP}=$ Picture package, $\mathrm{ETP}=$ Electronic teaching plan, EPA=Electronic photo album, EPABM=Electronic photo album combined with background music, OCOCU $=$ Online colleges of conventional universities, RTVUs= Radio \& television universities

Of four types of "Picture Show" module, "electronic photo album combined with background music" earns a satisfaction rate of $100 \%$, the highest of all columns in online courses. The phenomenon gives us a revelation that this mode is preferably employed for design and arrangement of pictures in online courses, because it largely draws students' attention, stimulate and cultivate students' learning motivation, meets students' need of autonomous learning, and in particular it can effectively increase click rate, download rate and appraisal scores of online courses.

\section{G. Module "Tests and Training"-a trump card to promote application of online courses}

From the finals of the Twelfth National Multimedia Courseware Contest, it is not hard to see that judges give top priority to "tests and training", for this module can precisely reflect application of modern educational technologies in online courses and have incomparable technological contents. Any courseware that reflects this technology by means of database has earned the highest score, since this technology forms the foundation for prize winners in courseware contest.

TABLE X. Survey of SAtisfaction with Modes of Presenting “TESTS \& TRAINING” OF ONLINE COURSES

\begin{tabular}{|c|c|c|c|c|}
\hline TY Types & PQRA & PQAS & CQCA & SSCA \\
\hline OCOCU & $12 \%$ & $18 \%$ & $36 \%$ & $94 \%$ \\
\hline RTVUs & $10 \%$ & $20 \%$ & $42 \%$ & $98 \%$ \\
\hline average & $11 \%$ & $19 \%$ & $39 \%$ & $96 \%$ \\
\hline
\end{tabular}

Key: SR=satisfaction rate, PQRA=Present questions and require students to give their answers, PQAS=Present all questions and answers simultaneously, CQCA=Click questions one by one and check answers, SSCA=Submit score after completing all questions, then check answers, OCOCU $=$ Online colleges of conventional universities, RTVUs= Radio \& television universities

Comparing modes of presenting the "tests and training" module, we find that the mode "submit score after completing all questions, then check answers" earns a highest satisfaction rate, averaged 96\%. In fact, 6 sets of our courseware adopting this mode of presentation have won at least second prizes when chosen to compete in the Twelfth National Multimedia Courseware Contest; to some extent, the presenting mode of this module has played a key role. 


\section{OPTIMAL MODES USED TO PRESENT FUNCTION MODULES OF QUALITY ONLINE COURSES}

\section{A. Modes of presenting the function modules based on increasing utilization of online courses}

By analyzing the modes used to present the function modules of online educational courses, we have concluded that presentation of modules in the development of online courses has already become the major trend for course development; however, optimization of course module presentation must be based on students' autonomous learning and the optimal presentation mode of each module must be determined using contrast analysis and content analysis. According to foregoing analysis, optimized presentation mode of functional modules of quality online courses may be epitomized as a "comparative and optimized presentation" mode; in other words, the existing presentation of each module is comparatively analyzed according to different course nature and learning object, then an optimal mode is chosen to use as final presentation mode of the module. Currently, quality online courses presented in this mode should abide by the following optimizing rules: 1) module "Directions for Use" is presented by the mode of "screenshot combined with positioning commentary"; 2) module "Learners' Guide" is presented by the mode of "chairing teacher IP trisection screen navigation or literal description combined with video commentary"; 3) module "Text" is presented by the mode of "bullets fold and click audio"; 4) module "Case Analysis is presented by the mode of "animated simulation combined with audio comments"; 5) module "video classroom" is presented by the mode of "IP trisection screen, covering audio, video, heading navigation switchover, free realization of forward and backward, fullrange electronic teaching plan presentation”; 6) module "picture show" is presented by the mode of "electronic photo album combined with background music"; and 7) module "test and training" is presented by the mode of "submit score after completing all questions, then check answers”. By this mode, dynamic integration of all seven modules can absolutely develop a high quality online course and fundamentally create a higher prize.

\section{B. Application effect of "comparative and optimized presentation" of high quality online courses}

According to basic philosophy of the "comparative and optimized presentation" mode, we conducted a questionnaire survey among students for courses measured up to seven modules of online courses developed in Shaanxi, and have ound the results essentially conforming to this mode.

TABLE XI. SURVEY OF SATISFACTION WITH MODES OF “COMPARATIVE AND OPTIMIZED PRESENTATION” OF QUALITY ONLINE COURSES

\begin{tabular}{|c|c|c|c|c|c|c|c|c|}
\hline FM & DU & LG & Txt & CA & VC & PS & TT & Av. \\
\hline SR & 76 & 83 & 78 & 82 & 89 & 86 & 86 & 83 \\
\hline
\end{tabular}

Key: FM= Functional modules, SR(\%)=Satisfaction rate, DU=Directions for Use, LG= Learner Guide, CA=Case Analysis, VC=Video Classroom, PS=Picture Show, TT=Tests \& Training, Av.=average
From the table above, the function module presentation mode of "comparative and optimized presentation" is basically applicable to students' autonomous learning, with an average satisfaction rate of $83 \%$. Module "Directions for Use" earns the lowest satisfaction rate, 76\%; module "Video Classroom" does the highest, $89 \%$. This suggests that quality online courses construction is a slow building-up process, requiring us to refine the design, increase the technological content and upgrade the overall quality of online courses during development and construction.

\section{Limitations of "comparative and optimized presentation" mode of quality online courses}

As a product of practice, the "comparative and optimized presentation" mode of quality online course modules is merely a building mode developed on the local scale by reference to national quality online courses and finals of the Twelfth National Multimedia Courseware Contest, and to some extent it is created under insufficient guidance of modern idea and theory of education. Major limitation of the mode is the lack of large-scale application and development, and in particular, the lack of verification in mass practice. [5]In addition, due to critical shortage of analytic argumentation data on presentation mode of online course modules, much of information cited in this paper, especially those sourced on websites, is only related information that is randomly targeted. Finally, online courses in China are still at the primary stage of construction; in spite of a great number, few of them are of high quality particularly due to serious problems including qualifications for the chairing teacher. So, it is unavoidable that individual error information appears in survey and statistics. In brief, we feel somewhat feeble when justifying some standpoints, for there is no unified planning and deployment by the government.

\section{REFERENCES}

[1] Zhang Huijie, Long Shili and Wang Renqing. Problems in Quality Courses Construction in China and Improvement Suggestions [J]. Distance Education in China, 2008, (11): 59-62.

[2] Document No. 1 [2003], Higher Education Division, MOE. Circular of the Ministry of Education on Initiating Quality Course Construction of Teaching Quality and Reform Project in Institutions of Higher Education (Z). http://www.jpkcnet.com.

[3] Zhao Na and Liu Mingzhuo. Survey of Student-based Online Courses Design and Application [J]. Distance Education in China, 2010, (06): 51-53.

[4] Hu Qintai and Hu Xiaoyong. Study on Quality Courses Website Construction in Universities - Take Education Communication [J]. China Education Info, 2009, (19): 22-25.

[5] Liu Zhixuan.Problems in Making Web-based Top-quality Courses for Distance Education and Solution[J].China Medlcal Education Technoloqy .2011,(04): 377-380 